\title{
rocedimentos didáticos para a apropriação do gênero hipertexto em cursos de Comunicação Social: uma abordagem sociodiscursiva
}

\author{
Adriana Cintra de Carvalho 1 \\ Francisco de Assis 2
}

\begin{abstract}
Resumo: Este trabalho se propõe a discutir a formulação de uma seqüência didática para o ensino do hipertexto, adotando procedimento metodológico um modelo de análise textual apresentado pelo Interacionismo Sociodiscursivo. A discussão mostra como a diversidade do hipertexto e a variabilidade de sua manifestação introduz dificuldades para defini-lo ou como um gênero ou como um macrogênero, bem como para identificar suas características a serem apropriadas pelo produtor de texto. Como resposta a essas barreiras, o artigo aponta alguns caminhos para a construção de um método de ensino de hipertexto em cursos de Comunicação Social, tomando como base o de Webdesign.
\end{abstract}

Palavras-chave: Gênero de texto; hipertexto; transposição didática; seqüência didática.

\begin{abstract}
This work aims to discuss the formulation of didatic sequence for teaching hypertext when adopting a methodological model presented by the sociodiscursive interacionism. The discussion tells us how hypertext diversity and its variability in terms of manifest reveal the difficulties to define the hypertext as a genre or a macrogenre as well as how to identify its characteristics when used by the author of the text. As a response to these barriers, this article intends to show some ways for developing a teaching method of hypertext in Social Communication courses using the web design as a reference.
\end{abstract}

1 Doutoranda em Lingüística Aplicada e Estudos da Linguagem pela Pontifícia Universidade Católica de São Paulo (PUC-SP). Mestre em Lingüística Aplicada pela UNITAU. Professora da UNITAU e da Faculdade Dehoniana. E-mail: dricacintra@itelefonica.com.br

2 Pós-graduando em Jornalismo Cultural pela UMESP. Bacharel em Comunicação Social, com habilitação em Jornalismo, pela UNITAU e pesquisador do Núcleo de Pesquisa e Estudos em Comunicação (NUPEC), da mesma instituição. Editor da revista Acervo On-line de Mídia Regional. E-mail: francisco-nupec@uol.com.br 
A tarefa de ensinar Língua Portuguesa a alunos de graduação principalmente no que diz respeito ao ensino dos os gêneros de texto relativos às atividades de linguagem do profissional que se pretende formar - se traduz numa busca por disponibilizar ao aluno um conjunto de artefatos sóciohistoricamente construídos, que, se apropriados por esse aluno, por si e para si, podem ser verdadeiros instrumentos para seu agir no mercado de trabalho.

Entendendo a apropriação desses gêneros como um mecanismo fundamental de socialização e de inserção prática dos alunos nas atividades comunicativas de sua profissão, defendemos a idéia de que um dos objetivos do ensino de Língua Portuguesa nos cursos de graduação é criar um meio favorável para que os alunos se apropriem de determinados gêneros de texto, o que exige do professor a capacidade de transpor os conhecimentos sobre tais gêneros do nível teórico para o nível didático.

No início do ano de 2007, recebemos o desafio de trabalhar, num curso de Webdesign, a Língua Portuguesa aplicada à produção do gênero digital chamado hipertexto. Consideramos um desafio porque sobre o hipertexto tínhamos apenas um pequeno conjunto de conhecimentos construídos a partir de nossas experiências de leitura de textos publicados na Internet e de outras obras de referência sobre o assunto.

Entre conhecimentos empíricos e conhecimentos necessários para ensinar graduandos a compor hipertextos, existe uma distância considerável. Além disso, a diversidade teoricamente ilimitada do hipertexto e a variabilidade de sua manifestação concreta também introduzem um problema de ordem teóricometodológica, que é o da definição particular desse gênero, de sua classificação e da identificação de suas características centrais que podem ser apropriadas pelos alunos. Dentro do macrogênero hipertexto, há vários subgêneros.

Ao estudarmos o hipertexto para ensiná-lo aos alunos, sentimos a necessidade da elaboração de procedimentos e de materiais didáticos adequados, como uma seqüência didática, que propiciasse a transposição didática dos conhecimentos científicos para o nível dos conhecimentos a serem efetivamente ensinados. Mas a maneira de proceder a isso foi para nós um grande problema, principalmente porque não encontramos sugestões de trabalho nas referências bibliográficas referentes à redação para web.

Com o objetivo de discutir alguns caminhos que percorremos rumo à construção de uma seqüência didática, elaboramos este artigo que se organiza em quatro itens. No primeiro, apresentaremos os aportes teóricos que sustentam nossa definição de gênero de texto; no segundo, apresentaremos a síntese dos conhecimentos científicos sobre hipertexto para configurá-lo como um gênero de texto; no terceiro, refletiremos sobre a importância da transposição didática e a emergência da seqüência didática como um procedimento de transposição didática e, no último, adotamos um modelo de análise de texto que poderá dar início à nossa seqüência didática.

\section{Gêneros de texto segundo o Interacionismo Sociodiscursivo}

Na definição do hipertexto como um gênero textual, assumimos o conceito de gênero construído pelo Interacionismo Sociodiscursivo (ISD), corrente teórica que resulta de um posicionamento epistemológico para compreender as condições do desenvolvimento humano sob uma perspectiva histórica de movimento constante. Segundo seu criador, Bronckart (2003; 2006), esse posicionamento está baseado nos teóricos Vygotsky, Voloshinov, Bakhtin, Spinoza 
e Marx, dentre os quais se destaca Vygotsky (2000), criador do Interacionismo Social. Os pressupostos fundamentais do Interacionismo Social de Vygotsky são:

a) Qualquer fato social, lingüístico, psicológico, entre outros, constrói-se com base em pré-construções, que são as práticas, conhecimentos e valores provenientes de gerações anteriores. Isso quer dizer que, quando agimos, retomamos uma língua, idéias, posturas, procedimentos, discursos e gêneros de texto que se encontram à nossa disposição, elaborados e fornecidos pelo meio social que nos constitui.

b) $\bigcirc$ desenvolvimento do psiquismo e da práxis humana efetua-se nas atividades sociais. $O$ ser humano age e desenvolve-se em interação com o outro. Dessa forma, a atividade social e os produtos dessa atividade seriam os fundamentos explicativos do agir humano.

c) A atividade de linguagem desempenha um papel essencial no desenvolvimento humano, contribuindo para representar as pré-construções e organizar, comentar e regular as ações e as interações humanas (BRONCKART, 2003; 2006). A atividade de linguagem se apresenta, inicialmente, como uma produção interativa associada às atividades sociais, sendo ela o instrumento pelo qual o ser humano, intencionalmente, emite interpretações relativas às propriedades do meio em que essa atividade se desenvolve. Esse princípio o ISD toma como próprio e, por isso, acrescenta ao sintagma "interacionismo social" o termo "discursivo".

O ISD, assim como o Interacionismo Social, propõe uma reflexão sobre o desenvolvimento humano, e para tanto, estuda o ambiente humano e suas préconstruções específicas, analisa os processos de mediação e de formação por meio dos quais são apropriadas determinadas pré-construções e investiga os efeitos dos processos de mediação e de transmissão das pré-construções na constituição da pessoa humana. (BRONCKART, 2003).

O estudo do ambiente humano, conforme Bronckart (2003), deve pesar sobre elementos principais que o constituem, como as atividades coletivas, as formações sociais e os textos.

As atividades coletivas podem ser divididas em atividades não-linguageiras e em atividades linguageiras e organizadas em formas concretas por causa dos contextos socio-históricos (BRONCKART, 2003). Essas formas concretas, chamadas formações sociais, geram regras, normas, valores a fim de regular as interações entre membros de um determinado grupo.

As atividades coletivas linguageiras correspondem empiricamente aos textos, que são produzidos com o recurso de uma língua natural. Para o ISD, os textos são unidades comunicativas globais, cujas características composicionais dependem das propriedades da situação de interação e das atividades gerais que elas comentam, assim como das condições socio-históricas de sua elaboração (BRONCKART, 2003). Os textos, produtos da atividade humana, veiculam uma mensagem lingüisticamente organizada e articulam-se às necessidades, aos interesses, às condições de funcionamento das formações sociais no seio das quais são produzidas, fazendo-se coerentes para os destinatários.

Esses textos são auto-suficientes do ponto de vista da ação e da comunicação e se distribuem em múltiplos gêneros de texto socialmente reconhecidos e adaptados a uma determinada situação comunicativa. Em outras palavras, no decorrer da história, no quadro das atividades coletivas linguageiras, foram e são produzidas determinadas formas comunicativas que, estabilizandose relativamente, constituem os gêneros de texto de uma esfera social.

Concluindo, Bronckart (2003) considera que todo indivíduo de uma determinada comunidade lingüística, ao agir com a linguagem, é confrontado permanentemente com um universo de textos pré-existentes, organizados em 
gêneros, que se encontram sempre em um processo de permanente modificação e que são em número teoricamente limitado. Desde o momento do nascimento, a exposição contínua aos gêneros vai construindo nos leitores e nos produtores um conhecimento intuitivo das regras e das propriedades específicas de diferentes gêneros, mesmo que de forma não consciente ou sistemática.

Essas regras e propriedades acabam por ser apropriadas e, como em todos os processos de aprendizagem social, acabam por sofrer modificações contínuas, conforme Bakhtin (1992) aponta, quando define os gêneros como formas relativamente estáveis de enunciados, construídas pelas esferas sociais. Desse modo os gêneros estão em permanente modificação, derivada não só das transformações das esferas sociais, mas também das transformações introduzidas pelos próprios produtores.

Considerando o conceito de gêneros de texto acima, podemos afirmar que o hipertexto é um deles. Mas configurá-lo não é tão fácil quanto parece, porque precisamos de um modelo de análise de texto. Antes que apresentemos esse modelo, o que faremos no item quatro deste artigo, veremos alguns conhecimentos teóricos sobre o hipertexto que devem ser sistematizados para chegarmos a uma transposição didática e a uma seqüência didática.

2. A linguagem da Internet e o gênero de texto chamado hipertexto

3 Conforme apontam autores que se dedicaram a compreender as características do hipertexto, como (DIAS, 1999), seu surgimento está intimamente ligado ao da escrita e, principalmente, ao da entronização do papel no mundo ocidental, no século 12, seguida da invenção da tipografia, no século 15 . Os recursos aplicados aos "livros modernos", produzidos em série e não mais escritos à mão, também se caracterizam como formas de hipertexto: paginação, sumário, citações, capítulos, títulos, resumos, palavraschave, erratas, bibliografia, entre outros, podem ser considerados como elementos de leitura não-linear, por possibilitarem uma interação entre texto e leitor.

4 Agência de Pesquisa e Projetos Avançados

A transformação da Internet em meio de comunicação de massa, ocorrida na segunda metade da década de 1990, provocou profundas transformações no modo de se pensar e de se fazer comunicação. Para se adequar à chamada sociedade digital - conceito que remete à popularização das novas tecnologias (LÉVY, 1999) -, a produção midiática precisou ser remodelada, em seus mais variados aspectos, que abrangem conteúdo, formato, linguagem, espaço e tempo.

Bem se sabe que a comunicação vivencia um momento de transição paradigmática: o modelo objetivista de produção - principalmente a jornalística - está abrindo espaço para novas demandas da sociedade, no que tange a conteúdo, forma, linguagem e, sobretudo, relacionamento com o grande público, que não quer apenas informações diferenciadas e qualificadas, mas também quer ser parceiro dos processos de construção das informações.

Os próprios elementos que compõem a estrutura de sites e portais sugerem ao internauta uma liberdade para decidir como irá conduzir a leitura, de acordo com suas vontades e seus interesses. Por isso mesmo, embora não seja um recurso exclusivo do ciberespaço $\mathbf{3}$, o hipertexto se tornou um sinônimo para aquele link capaz de transportar de uma página para outra, dentro da rede mundial de computadores, propiciando a prática de uma leitura não-linear. Numa visão acadêmica, Xavier (2005, p. 171) entende que o hipertexto é "uma forma híbrida, dinâmica e flexível de linguagem que dialoga com outras interfaces semióticas, adiciona e acondiciona à sua superfície formas outras de textualidade".

Para que se possam compreender as características do hipertexto no espaço virtual, é necessário voltar no tempo e conhecer um pouco da história da rede mundial de computadores. Ferrari (2003) conta que o site, tal qual se conhece atualmente, foi criado durante a década de 1980 e aprimorado no início dos anos 1990: trata-se da Word Wide Web (Rede de Abrangência Mundial), cuja estrutura foi idealizada à luz do hipertexto e de outros recursos anteriormente criados para a Internet.

A Internet havia sido desenvolvida nos Estados Unidos, em 1969, no auge da Guerra Fria, pela Advanced Research Projects Agency 4 (Arpa), órgão do Departamento de Defesa norte-americano. O objetivo era possibilitar uma 
comunicação emergencial entre os militares, na eventualidade da nação ser atacada pela extinta União Soviética ou por outro país.

Nas décadas seguintes, vários recursos foram aprimorados e, em 1986, foi criada uma rede chamada backbone $\mathbf{5}$, capaz de transferir dados via computadores, sistema de voz, fibras ópticas, microondas, etc. Porém, no final dos anos 1980, o acesso a esse "mundo novo" ainda era restrito aos serviços de inteligência e a universidades e centros de pesquisa. Foi nesse cenário que, em 1989, após anos de criação, o pesquisador Tim Berners Lee propôs a utilização da Word Wide Web, parte multimídia da Internet que permite ao usuário trocar e compartilhar informações.

Ainda segundo Ferrari, para aprimorar sua criação, Lee contou com a colaboração quase imediata de Robert Cailliau; posteriormente, em 1992, quem entra em cena para aperfeiçoar seu trabalho foi o designer e pesquisador Jean François Groff que o convidou para ser o primeiro aluno do projeto InfoDesign, que ofereceu valiosa contribuição para a configuração gráfica da WWW.

Em pouco tempo, a Internet se alastrou pelos quatro cantos do globo. Quatro anos mais tarde, em 1996, já chegava em 56 milhões o número de usuários no mundo; hoje, estima-se 747 milhões de pessoas $\mathbf{6}$, com mais de 15 anos, acessam a rede regularmente.

Tendo em vista o "sucesso" desse fenômeno midiático, é certo que os avanços tecnológicos promovem o surgimento e a adequação de novos modelos de comunicação, em uma constante busca pela excelência. Se existem ferramentas e suportes que permitem ao usuário navegar com facilidade por esse universo, suas características são fortes fatores a serem considerados na leitura sobre a nova linguagem criada pela Internet.

Em primeiro lugar, a navegabilidade parece ser a questão-chave para o processo de utilização do espaço virtual. Furquim (2004, p. 51), por exemplo, mostra que um dos principais responsáveis pelo sucesso de um site é sua "arquitetura”, uma vez que "é 'odioso' para o usuário não conseguir encontrar no site web uma informação que ele sabe que está lá". Ao analisar os fatores que estimulam a utilização desse espaço, a autora o planejamento e o "desenvolvimento de funcionalidades" devem ser as principais preocupações de quem se propõe a montar uma página na Internet.

A partir daí, pode-se trazer à tona uma outra questão: em razão de suas dimensões temporais e conteudísticas, um site, para atender às expectativas de seus visitantes, deve manter visíveis todas das ferramentas que possibilitem sua compreensão e sua manipulação. Para isso, é preciso que a hierarquização de informações esteja posicionada de forma clara e que o recurso dos links constitua uma relação de contexto entre o primeiro e o segundo texto. "Pois, o que os links evidenciam são as opções associativas que na leitura de um texto qualquer - leitor articula a partir de seus conhecimentos prévios, sua ideologia etc." (CAVALCANTE, 2005, p. 168).

Por outro lado, assim como foi dito anteriormente, o público já não quer

5 Backbone (espinha dorsal) é uma via de interligação de sub-redes da Internet. Ferrari (2003) exemplifica a explicação ao dizer que, no Brasil, a Fundação de Amparo à Pesquisa do Estado de São Paulo (Fapesp) se interliga diretamente com os Estados Unidos por intermédio desse sistema.

6 Dados levantados pela empresa norte-americana de pesquisas de mercado comScore Networks com base em janeiro de 2007 . O levantamento apontou um crescimento de 10\% com relação a janeiro de 2006 . apenas receber informações no posto de receptor; ele quer ter autonomia para "recortar" seu próprio mundo. Isto é fato. Mesmo assim, ainda há controvérsias sobre sua real capacidade de participar do processo de produção e edição de informações.

Synder (apud MARCUSCHI, 2001) acredita que os suportes oferecidos para o navegador traçar seu próprio caminho não é o suficiente para que haja uma ruptura pragmática dos conceitos já estabelecidos entre escrita e leitura. $\bigcirc$ que se tem é apenas a sensação de uma "autoria coletiva", correlativo a um processo de leitura dinâmica, em que leitor determina a ordem e não o conteúdo do que está publicado. 
Ao se mover livremente, navegando por uma rede de textos, o leitor procede a um descentramento do autor, fazendo de seus interesses de navegador o fio organizador das escolhas e das ligações. Certamente, o leitor procede por associações de idéias que o conduzem a sucessivas escolhas, produzindo uma textualidade cuja coerência tem um toque pessoal. Pode-se até mesmo dizer que não há, efetivamente, dois textos iguais, na escritura hipertextual. Hoje se pode partir para uma nova ligação desde que prevista pelo autor do hipertexto. Caso uma ligação não esteja sinalizada, o navegador não pode acessar nada por aquele caminho (MARCUSCHI, 2001, p. 96-97).

Interessante observar que o hipertexto possibilita ao internauta navegar por mais de um site enquanto faz a leitura de um único assunto. Ele pode muito bem começar a ler um texto na página $\mathrm{A}$, acessar um link que o transporte para o site $B$ e, de lá, partir para um terceiro ou para mais ambientes de rede, que o conduzam a um desfecho, no momento em que ele próprio considerar oportuno.

Mas a falta de motivos para se estabelecer um novo paradigma, apontada por Synder, é rebatida por Primo (2003, p. 39), que faz uma distinção nas relações estabelecidas nos ambientes hipertextuais. Para ele, além do "hipertexto potencial”, situação em que apenas o leitor modifica seu olhar e o texto permanece intacto, existem duas outras vertentes, denominadas por ele como "hipertexto cooperativo" e "hipertexto colaborativo", desenvolvidos em grupos virtuais:

No hipertexto cooperativo todos os envolvidos compartilham a invenção do texto comum, à medida que exercem e recebem impacto do grupo, do relacionamento que constroem e do próprio produto criativo em andamento. Já o hipertexto colaborativo constitui uma atividade de escrita coletiva, mas demanda mais um trabalho de administração e reunião das partes criadas em separado do que um processo de debate (nesses casos, inclusive, uma única pessoa pode assumir as decisões de publicar).

Como já pôde ser observado até aqui, a Internet, de modo geral, e os sites, por delimitação, agregaram novas características àquele hipertexto originado junto com a escrita. Aliás, hoje em dia o comum, na web, é a utilização do termo hipermídia, um tipo de hipertexto que se interconecta com plataformas de textos, sons, imagens e vídeos, numa tradução vulgar da definição de Negroponte ( 1995 , p. 66): "Pense na hipermídia como uma coletânea de mensagens elásticas que podem ser esticadas ou encolhidas de acordo com as ações do leitor. As idéias podem ser abertas ou analisadas com múltiplos níveis de detalhamento".

Se há um acordo entre pesquisadores e profissionais do mercado é que essa característica pluritextual está intimamente ligada ao gênero site. $\bigcirc$ internauta, por sua vez, busca a rede mundial de computadores, para múltiplos fins, sabendo que ali encontrará recursos das mais diferentes naturezas. $E$, na realidade, tudo isso é o que caracteriza o ciberespaço como ambiente onde signos distintos se entrelaçam.

O ciberespaço, dispositivo de comunicação interativo e comunitário, apresenta-se como um instrumento dessa inteligência coletiva. É assim, por exemplo, que os organismos de formação profissional ou à distância desenvolvem sistemas de aprendizagem cooperativa em rede [...] Os pesquisadores e estudantes do mundo inteiro trocam idéias, artigos, imagens, experiências ou observações em conferências eletrônicas organizadas de acordo com interesses específicos (LÉVY, 1999, p. 29).

É indiscutível que a Internet possui uma linguagem própria. Sua estrutura permite a convergência de imagem, som e texto num mesmo espaço, somando ainda a possibilidade de o internauta agir conforme seus próprios objetivos. E é por isso que a elaboração de recursos hipertextuais deve levar em consideração todos os aspectos teóricos que norteiam a existência da rede mundial de computadores, bem como as demandas geradas pela sociedade midiática.

Mas como ensinar isso ao aluno de Webdesing? 
Segundo Schneuwly (apud MACHADO \& CRISTÓVÃO, 2006), no processo de desenvolvimento dos indivíduos, sua participação em diferentes atividades sociais vai Ihes possibilitando a construção de conhecimentos sobre os gêneros e sobre os esquemas para sua utilização. Entretanto, se os gêneros mais informais vão sendo apropriados no decorrer das atividades cotidianas, sem necessidade de ensino formal, os gêneros mais formais, como o hipertexto, necessitam ser aprendidos mais sistematicamente.

O processo sistemático de ensino-aprendizagem do hipertexto exigiu de nós uma transposição didática e uma seqüência didática, as quais foram apenas iniciadas e estão em construção.

\section{Transposição didática e seqüência didática no ensino do} hipertexto

Tudo o que foi discutido acima é no mínimo abstrato para ser tomado como um conjunto de prescrições para a redação do hipertexto. Esses conhecimentos apresentados precisam passar por uma transposição didática. $\mathrm{O}$ termo transposição didática é compreendido por nós como o conjunto das transformações que um determinado conjunto de conhecimentos científicos necessariamente sofre, quando temos o objetivo de ensiná-lo.

Machado e Cristóvão (2006), duas pesquisadoras preocupadas com o ensino de gêneros, consideram que há três níveis básicos nas transformações por que o conhecimento científico passa: no primeiro, há o "conhecimento científico" propriamente dito, que sofre um primeiro processo de transformação para constituir o "conhecimento a ser ensinado", que, finalmente, ainda se transforma em "conhecimento efetivamente ensinado" e que, inevitavelmente ainda se constituirá em "conhecimento efetivamente aprendido".

Com relação a esses níveis, enfrentamos alguns problemas durante o processo de ensino do hipertexto. Problemas que já haviam sido discutidos pelas autoras citadas anteriormente.

O primeiro problema que surgiu ainda no primeiro nível diz respeito à própria seleção dos conteúdos a serem ensinados, uma vez que essa seleção resultou da mistura do conhecimento científico com o conhecimento das práticas sociais de linguagem. Essa mistura nos fez pensar que estávamos dando ao ensino uma abordagem submetida ao senso comum ou à ideologia dominante.

O segundo problema detectado a partir desse primeiro nível de transposição didática foi o processo de autonomização de determinados objetos do conhecimento científico que, inevitavelmente, foram separados da teoria global e da problemática científica em que surgiram e em que ganharam seu sentido específico. Em razão disso, outras significações foram atribuídas ao hipertexto.

O terceiro problema em relação à transposição didática, desde o seu primeiro nível, é o da compartimentação dos conteúdos selecionados: o hipertexto era visto separadamente nos seus aspectos enunciativos, estruturais, pragmáticos, etc.

Diante desses problemas, sentimos a necessidade de desenvolvermos uma seqüência didática, que aqui definimos como um conjunto de procedimentos metodológicos e de atividades progressivas, planificadas, guiadas por um objetivo geral, qual seja a produção de um hipertexto.

A primeira atividade desse conjunto de atividades progressivas é a identificação do que o aluno já sabe e do que precisa aprender sobre o hipertexto. São oferecidos exercícios de leitura que primam mais pela indução. Por meio deles, o aluno compara, percebe semelhanças e diferenças, generaliza, estabelece relações entre hipertextos. Essa primeira atividade termina com a produção de 
um hipertexto, cujo produto deve ser visto como ponto de partida para a seleção de atividades que deverão ser trabalhadas com os alunos.

Depois vem a exploração dos vários elementos do gênero hipertexto (condição de produção, conteúdo temático, forma de organização, polifonia e inserção de vozes e marcas lingüísticas), construídos a partir do modelo de análise de texto apresentado no item seguinte deste artigo.

O último conjunto de atividades visa a finalizar o projeto com a reescrita do hipertexto.

Para a construção dessa seqüência didática, logo se tornou evidente a necessidade da construção prévia de um "modelo didático de gênero", que pudesse guiar a elaboração das atividades planificadas.

O "modelo didático de gênero" é um objeto descritivo e operacional, construído para apreender o fenômeno complexo da aprendizagem de um gênero (MACHADO \& CRISTÓVÃO, 2006). A construção desse modelo de gênero permite a visualização das dimensões constitutivas do gênero e seleção das que podem ser ensinadas e das que são necessárias para um determinado nível de ensino.

\section{Modelo didático do hipertexto}

A construção do modelo didático do hipertexto não precisa ser teoricamente perfeita. Ela deve se abrir à possibilidade da utilização de referências teóricas diversas, de diferentes estudos sobre o gênero a ser ensinado, além de referências obtidas por meio da observação e da análise de práticas sociais que envolvam o gênero, junto a especialistas na sua produção, como expusemos no item dois deste artigo.

Além de levar em conta todas essas referências, a construção do modelo didático implica a análise de um conjunto de textos que se considera como pertencentes ao gênero. Como procedimentos de análise de textos, para esta pesquisa, escolhemos os que foram propostos por Bronckart (2003). Dentre esses procedimentos, temos os seguintes: análise das condições de produção do texto; análise da arquitetura interna dos textos, na qual se distinguem três níveis (o da infra-estrutura textual, o dos mecanismos de textualização e o dos mecanismos enunciativos).

As condições de produção podem ser definidas como o conjunto de parâmetros que podem exercer uma influência sobre a forma como um texto é organizado: quem é o emissor, em que papel social se encontra, a quem se dirige, em que papel se encontra o receptor, em que local é produzido, em qual instituição social se produz e circula, em que momento, em qual suporte, com qual objetivo, em que tipo de linguagem, qual é a atividade não verbal a que se relaciona, qual o valor social que Ihe é atribuído, etc.

A infra-estrutura geral do texto engloba o plano mais geral do texto, os tipos de discurso que comporta, modalidades de articulação entre esses tipos de discurso e seqüências que nele eventualmente aparecem.

O plano mais geral refere-se à organização de conjunto do conteúdo temático, mostra-se visível no processo de leitura e pode ser codificado em um resumo, e os tipos de discurso são formas de organização do mundo discursivo em relação ao contexto de enunciação.

Todo e qualquer texto é organizado por tipos de discurso, que apresentam relação com o contexto físico e constituem segmentos de texto marcados lingüisticamente, sendo diferentes entre si. Destacam-se o discurso interativo, o discurso teórico, o discurso relato-interativo e o discurso narrativo (BRONCKART, 2003).

Discurso interativo é o segmento de texto que apresenta primeira e segunda pessoa do discurso (eu e tu) e verbo no tempo presente pontual. $\bigcirc$ mundo 
discursivo se passa no mesmo tempo do mundo real, marcado pelo aqui e agora. Discurso teórico é o segmento de texto em que desaparecem os dêiticos (eu, tu, aqui e agora). Discurso relato-interativo é o segmento de texto em que o mundo discursivo está disjunto do mundo real. Os verbos aparecem no tempo passado, mas numerosas unidades lingüísticas referem-se diretamente às personagens agentes dessa interação (eu e tu). Discurso narrativo é o segmento de texto em que nenhuma unidade lingüística faz referência aos agentes produtores. Nele o mundo discursivo está disjunto do mundo real.

As seqüências são formas de organização do conteúdo. Podem ser narrativas, explicativas, argumentativas e não aparecem obrigatoriamente nos textos. Os mecanismos de textualização envolvem a coesão nominal e a coesão verbal, e os mecanismos enunciativos, as vozes e modalizações.

A enumeração dos elementos a serem analisados não deve ser exaustiva nem rígida. Admitimos que, no próprio decorrer da análise, encontramos outros elementos que são fundamentais para a caracterização do hipertexto, como a objetividade, a navegabilidade, a visibilidade, a linguagem jornalística e publicitária, a página-plataforma, o processo de sumarização e distribuição dos conteúdos, os links etc.

Por fim, o que queremos dizer é que não aceitamos que os dados concretos do hipertexto sejam ajustados para que caibam dentro do modelo proposto. As próprias atividades efetivamente desenvolvidas na seqüência didática poderão exigir um retorno ao modelo didático para modificá-lo no que for necessário, considerando-se, assim, que esse modelo jamais é definitivo, mas sim, que se encontra em um processo contínuo de transformação.

\section{Consideraçōes finais}

Os conhecimentos construídos sobre o hipertexto estarão sempre correlacionados às representações que os alunos têm sobre as situações sociais diversas em que sentem necessidade de ler e/ou produzir esse gênero. E é com base nesses conhecimentos que o produtor escolhe um gênero particular que Ihe parece ser o mais adequado a uma determinada situação. Esse processo, porém, não é uma simples reprodução de modelos.

Mesmo tomando um modelo preexistente de hipertexto, a produção textual não vai ser uma reprodução exata desse modelo. Uma vez que as situações de ação da linguagem são sempre diferentes, o produtor vai sempre adaptar o texto aos valores particulares da situação em que se encontra. Sem contar que o meio físico Internet restringe certas escolhas. É preciso que o aluno tenha conhecimento dos aspectos tecnológicos desse meio. Nem tudo que o produtor gostaria de produzir é viável tecnicamente.

Essa adaptação poderá trazer conseqüências sobre os diferentes níveis do texto: na sua organização interna, nos mecanismos enunciativos, nos mecanismos de textualização. Ao final do processo, o texto produzido acabará por ser dotado de um estilo particular. Assim, toda produção pode contribuir para a modificação do gênero.

$\mathrm{Na}$ realidade, estamos diante de um processo de adaptação de um determinado gênero, gerador de novos exemplares de textos, mais ou menos diferentes dos modelos pré-existentes. E é pelo acúmulo desses processos individuais que os gêneros se modificam continuamente e assumem um estatuto fundamentalmente dinâmico e histórico.

O professor exerce o papel de mediador entre o aluno e os conhecimentos sistemáticos do gênero, por meio da seqüência didática que desenvolve. $\bigcirc$ processo de apropriação e adaptação é o aluno que realiza, quando acredita que necessita aprender aquele gênero para aperfeiçoar suas atividades linguageiras.

Como última consideração, defendemos que a atividade de reescritura do hipertexto é imprescindível como auto-avaliação, e as demais atividades da seqüência didática poderão criar os critérios para a reescrita do texto final. 


\section{Referências bibliográficas}

BAKHTIN, M. M. (1992). Estética da criação verbal. São Paulo: Martins Fontes.

BRONCKART, J. P. (2006). Atividade de linguagem, discurso e desenvolvimento humano. Campinas, SP: Mercado de Letras.

(2003). Atividade de linguagem, textos e discursos: por um interacionismo sociodiscursivo. São Paulo: EDUC.

CAVALCANTE, M. C. B. (2005). Mapeamento e produção de sentido: os links no hipertexto. In: MARCUSCHI, L. A.; XAVIER, A. C. Hipertexto e gêneros digitais. 2. ed. Rio de Janeiro: Lucerna. p. 163-169.

DIAS, C. A. (1999). Hipertexto: evolução histórica e efeitos sociais. Revista Ciências da Informação, Brasília, DF, v. 28, n.3, set./dez, pp. 269-277.

FERRARI, P. (2003). Jornalismo digital. São Paulo: Contexto, 2003.

FURQUIM, T. A. (2004). Fatores motivadores de uso de site web: um estudo de caso. Revista Ciências da Informação, Brasília, DF, v. 33, n. 1, jan./abr, pp. 48-54.

LÉVY, P. Cibercultura. Rio de Janeiro: Ed. 34, 1999.

MACHADO, A. R; CRISTOVÃO, V. L. L. (2006). A construção de modelos didáticos de gêneros: aportes e questionamentos para o ensino de gêneros. Revista Linguagem em (Dis)curso, Tubarão, SC, v. 6. número especial, set./dez.

MARCUSCHI, L. A. (2001). O hipertexto como um novo espaço de escrita em sala de aula. Linguagem \& Ensino, Pelotas, RS, v. 4, n. 1, pp. 79-111.

NEGROPONTE, N. (1995). A vida digital. São Paulo: Companhia das Letras. PRIMO, A. (2003). Quão interativo é o hipertexto? Da interface potencial à escrita coletiva. Fronteiras: Estudos Midiáticos, São Leopoldo, RS, v. 5, n. 2, pp. $125-142$.

VYGOTSKY, L. S. (2000). A construção do pensamento e da linguagem. São Paulo: Martins Fontes.

XAVIER, A. C. (2005). Leitura, texto e hipertexto. In: MARCUSCHI, L. A.; XAVIER, A. C. Hipertexto e gêneros digitais. 2. ed. Rio de Janeiro: Lucerna. pp. $170-180$. 